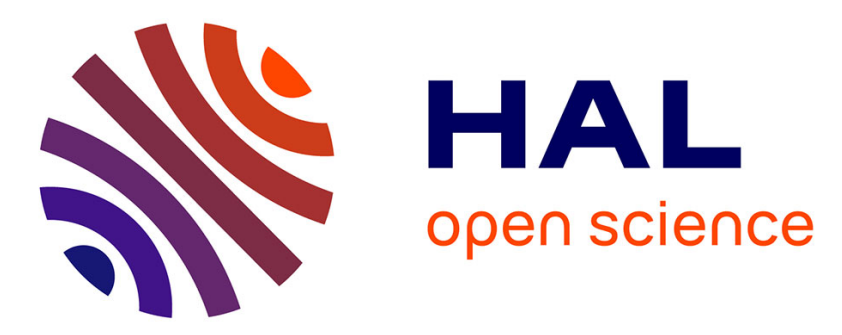

\title{
Sequential infiltration analysis of infiltration curves measured with disc infiltrometer in layered soils
}

\author{
D Moret-Fernández, B Latorre, L Lassabatere, S Di Prima, M Castellini, D
}

Yilmaz, Rafaël Angulo-Jaramillo

\section{- To cite this version:}

D Moret-Fernández, B Latorre, L Lassabatere, S Di Prima, M Castellini, et al.. Sequential infiltration analysis of infiltration curves measured with disc infiltrometer in layered soils. Journal of Hydrology, 2021, 600, pp.126542. 10.1016/j.jhydrol.2021.126542 . hal-03384601

\author{
HAL Id: hal-03384601 \\ https://hal.science/hal-03384601
}

Submitted on 19 Oct 2021

HAL is a multi-disciplinary open access archive for the deposit and dissemination of scientific research documents, whether they are published or not. The documents may come from teaching and research institutions in France or abroad, or from public or private research centers.
L'archive ouverte pluridisciplinaire HAL, est destinée au dépôt et à la diffusion de documents scientifiques de niveau recherche, publiés ou non, émanant des établissements d'enseignement et de recherche français ou étrangers, des laboratoires publics ou privés. 
When citing, please refer to the published version:

Moret-Fernandez, D., Latorre, B., Lassabatère, L., Di Prima, S., Castellini, M., Yilmaz, D., Angulo-Jaramillo, R., 2021. Sequential infiltration analysis of infiltration curves measured with disc infiltrometer in layered soils. Journal of hydrology, 600: 126542. https://doi.org/10.1016/j.jhydrol.2021.126542

\title{
Sequential infiltration analysis of infiltration curves measured with disc infiltrometer in layered soils
}

by

\author{
Moret-Fernández, D. ${ }^{1,2^{*}}$, Latorre, B. ${ }^{1}$, Lassabatere, L. ${ }^{3}$, Di Prima, $\mathrm{S}^{4}$., \\ Castellini, M. ${ }^{5}$, Yilmaz, D. ${ }^{6}$, Angulo-Jaramilo, R. ${ }^{3}$
}

${ }^{1}$ Departamento de Suelo y Agua, Estación Experimental de Aula Dei, Consejo Superior de Investigaciones Científicas (CSIC), PO Box 13034, 50080 Zaragoza, Spain

${ }^{2}$ Instituto Pirenaico de Ecología (CSIC), Av. Montañana 1005, P.O. Box 13.034, 50080 Zaragoza, Spain

${ }^{3}$ Univ Lyon, Université Claude Bernard Lyon 1, CNRS, ENTPE, UMR5023 LEHNA, F69518, Vaulx-en-Velin, France

${ }^{4}$ Department of Agricultural Sciences, University of Sassari, Viale Italia, 39, 07100 Sassari, Italy

${ }^{5}$ Council for Agricultural Research and Economics-Research Center for Agriculture and Environment (CREA-AA); mirko.castellini@crea.gov.it

${ }^{6}$ Munzur University, Engineering Faculty, Civil Engineering Department, 62000 Tunceli, Turkey

* Corresponding author. E-mail: david@eead.csic.es Tel.: (+34) 976716140 
2 Sequential infiltration analysis of infiltration curves measured with disc infiltrometer in layered soils

4

Moret-Fernández, D. ${ }^{1,2^{*}}$, Latorre, B. ${ }^{1}$, Lassabatere ${ }^{3}$, L., Di Prima, S $^{4}$, Castellini, M. ${ }^{5}$, 6 Yilmaz, D. ${ }^{6}$, Angulo-Jaramilo ${ }^{3}, \mathbf{R}$.

7

$8{ }^{1}$ Departamento de Suelo y Agua, Estación Experimental de Aula Dei, Consejo Superior de 9 Investigaciones Científicas (CSIC), PO Box 13034, 50080 Zaragoza, Spain

$10{ }^{2}$ Instituto Pirenaico de Ecología (CSIC), Av. Montañana 1005, P.O. Box 13.034, 50080

11 Zaragoza, Spain

$12{ }^{3}$ Univ Lyon, Université Claude Bernard Lyon 1, CNRS, ENTPE, UMR5023 LEHNA, F13 69518, Vaulx-en-Velin, France

$14{ }^{4}$ Department of Agricultural Sciences, University of Sassari, Viale Italia, 39, 07100 Sassari, 15 Italy

${ }^{5}$ Council for Agricultural Research and Economics-Research Center for Agriculture and

17 Environment (CREA-AA); mirko.castellini@crea.gov.it

${ }^{6}$ Munzur University, Engineering Faculty, Civil Engineering Department, 62000 Tunceli,

19 Turkey

* Corresponding author. E-mail: david@eead.csic.es Tel.: (+34) 976716140 
The soil sorptivity, $S$, and saturated hydraulic conductivity, $K_{s}$, can be estimated from the inverse analysis of a cumulative infiltration curve using the quasi-exact implicit (QEI) formulation or its corresponding 4-Terms (4T) approximation. Although these models consider the soil as homogeneous media, there is no information about how heterogeneous profiles can affect the inferred soil properties. This work analyzes the influence of layered soils on $K_{s}$ and $S$ estimates using QEI and 4T models, and designs a new procedure for treating infiltration curves measured on layered soil profiles. The Sequential Infiltration Analysis (SIA) method considers a sequence of increasing time series from the cumulative infiltration data to estimate $K_{s}$ and $S$, and its corresponding RMSE as a function of the number of samples used. A procedure to estimate the thickness of the upper uniform soil layer from the estimated wetting front advance (WFA) is also reported. The SIA method was applied on: (i) synthetic homogeneous profiles of loam soil and six layered profiles involving a 1,2 and $3 \mathrm{~cm}$ thickness loam layer over silty or sandy loam soils, respectively, (ii) stratified laboratory soil columns, and (iii) 20 experimental infiltrations performed in a semiarid region of North-Eastern Spain. Similar results were found between QEI and 4T models for all cases. Erroneous estimates of $K_{s}$ and $S$ were observed when the total infiltration time series was considered for the analysis, regardless of the presence of soil layering. In opposite, estimates improved when the SIA method was applied to the layered systems. The SIA method exploits the fact that the RMSE increases when the wetting front reaches the interface between the soil layers. Such increase allows: (i) detection of the soil heterogeneity, (ii) determination of the infiltration time, $t_{o}$, required for the wetting front to reach the lower layer, and, (iii) accurate estimates of the upper layer $K_{s}$ and $S$ along with its thickness. Laboratory experiments on layered soils and field measurements demonstrated that the SIA method could be satisfactorily applied on different curves with contrasting shapes and magnitudes. Although soil layering encountered on most 
47 field samplings restricted the treatment of the observed infiltrations to short-medium times, the SIA method allowed robust estimates of $K_{s}$ and $S$. These results indicate that the proposed method is a promising tool for characterizing the hydraulic properties of layered and heterogeneous soil profiles.

Keywords: Sorptivity; Hydraulic conductivity; Infiltration; Heterogeneous soil profiles

\section{INTRODUCTION}

Measurements of the soil surface hydraulic properties is crucial to solve many hydrological engineering and environmental issues linked to soil water storage and transport in the vadose zone. The tension disc infiltrometer (Perroux and White, 1988) has become a popular infiltration method because of the portable and its easy in-situ applicability (Angulo-Jaramillo et al., 2000). This instrument consists of a disc base attached to a water-supply reservoir and a bubbling tower to impose a negative pressure head $(h)$ at the disc base (Perroux and White, 1988). The soil hydraulic properties, sorptivity $(S)$ and hydraulic conductivity $\left(K_{s}\right)$, are commonly calculated from the cumulative water-infiltration curve measured with the disc infiltrometer. To this end, methods based on the transient state data analysis can be employed. The main advantage of the transient methods, compared to water steady-state based procedures (Ankeny et al., 1991; Lassabatere et al., 2006), is that they allow shorter experiments, which involves smaller sampled soil volumes, and hence a more homogeneous soil and initial water content profile (Angulo-Jaramillo et al., 2000).

Among the different water transient models, the quasi-exact implicit (QEI) analytical formulation of Haverkamp et al. (1994) has become one of the most popular methods to 
estimate the soil hydraulic properties (e.g., Lassabatere et al., 2009; Latorre et al., 2015, Fernandez-Galvez et al., 2019). The Haverkamp et al. (1994) model was extended to 3D disc infiltrometer measurements by Smettem et al. (1994) involving the following input parameters: $K_{s}, S$, the radius of the disc, $r_{d}$, the $\beta$ and $\gamma$ constants, and the initial and final volumetric water contents, $\theta_{i}$ and $\theta_{s}$ (Haverkamp et al., 1994; Smettem et al., 1994). The $\beta$ shape parameter is related to the soil diffusivity, $D(\theta)$, and the soil hydraulic conductivity functions. The constant $\gamma$ is related to the effect of the disk radius and gravity as well as the approximate estimation of sorptivity (Haverkamp et al., 1994, Smettem et al., 1994). Under regular conditions, a constant $\beta$ and $\gamma$ values of 0.6 and 0.75 , respectively, are employed (Angulo-Jaramillo et al., 2019; Lassabatere et al. 2009; Latorre et al., 2018, Moret-Fernández et al., 2020). In order to simplify the mathematics reducing the number of input variables, Lassabatere et al. (2006) proposed packing $\Delta \theta, r_{d}$ and $\gamma$ into the $A=\frac{\gamma}{r_{d}\left(\theta_{s}-\theta_{i}\right)}$ term.

Given that direct formulations are more convenient than complex implicit equations, Haverkamp et al. (1994) proposed the simplified two-Terms (2T) approximation for their quasi-exact implicit (QEI) formulation. However, such an approximation remains valid only for short to intermediate infiltration times. Although this simplified model has been largely employed for characterizing soils (Vandervaere et al., 2000; Lassabatere et al., 2006; MoretFernández et al., 2013), its reduced temporal validity makes its use uncertain. To solve this limitation, Latorre et al. (2105) determined the soil hydraulic properties form the inverse analysis of the QEI model, instead of using approximations like in BEST methods (Lassabatere et al., 2006, Yilmaz et al., 2010, and Bagarello et al., 2014). On their track, Fernandez-Galvez et al. (2019) compute a new version of BEST that makes use of the QEI formulation. However, such formulation is implicit and could lead to numerical indetermination while slowing down the inversion procedure. Given those difficulties, MoretFernández et al. (2020) suggested estimating $K_{s}$ and $S$ using the three-Terms (3T) and four- 
Terms (4T) approximations of the QEI formulation. These expansions are more accurate than the $2 \mathrm{~T}$, since they incorporate more terms, and thus remain valid over larger time intervals. Besides, the $4 \mathrm{~T}$ model presents four degrees of freedom and thus the potential to estimate the four input variables: $K_{s}, S, \gamma$ and $\beta$. However, Moret-Fernández et al. (2020) demonstrated that the inversion was affected by equifinality and non-uniqueness due to the small contribution of the fourth term to the bulk infiltration. Consequently, constant $A=\frac{\gamma}{r_{d}\left(\theta_{s}-\theta_{i}\right)}$ and $\beta$ values are required in the inverse analysis of experimental infiltration curves measured with contact sand layer. As a corollary, because of $\gamma$ and $\beta$ values are strongly linked, unrealistic hydraulic properties values could be obtained.

Most models developed for water infiltration consider isotropic and homogeneous porous media. This means that soil hydraulic properties and initial water content are considered uniform in all directions. However, soil heterogeneity in the field is more the rule than the exception and this may strongly impact cumulative infiltrations (Iovino et al., 2017; Lassabatere et al., 2010; Lassabatere et al., 2014; Angulo-Jaramillo et al., 2019). For instance, double-slope infiltration curves may be obtained in case of hydrophobicity (Lassabatere et al., 2019) or infiltration curves with extra-concavity may be obtained due to soil sealing and the concomitancy of several layers (Di Prima et al., 2018). In these cases, the application of models based on soil uniformity can result in erroneous estimates of the soil hydraulic properties (Angulo-Jaramillo et al., 2019).

Given the scarce information on the application of inverting methods developed for uniform soils to non-uniform and layered soils, the objective of this work is to study the influence of layered profiles on $K_{S}$ and $S$ estimates obtained by fitting QEI, or its approximate expansions, to infiltration data. The second objective is the development of a procedure for an appropriate characterization of the soil hydraulic properties of the upper soil layer and to approximate its 
thickness. To this end, both the QEI and 4T models were fitted to infiltration curves obtained (experimentally or numerically) in homogenous and layered soil profiles. The procedure implements a sequential analysis of the infiltration data series by fitting the model to an increasing number of samples and reporting the evolution of the quality of the fit or the RMSE. The best fit, characterized by the minimum RMSE, identifies the values of $K_{s}$ and $S$ from the upper layer, and provides the optimum infiltration time from which the thickness of the upper layer is also estimated. The new method, referred to as SIA for Sequential Infiltration Analysis, was validated using numerically generated data, laboratory experiments with homogeneous and layered soil profiles, and also real field data.

\section{THEORY}

\subsection{Cumulative infiltration curve equations}

The 3D cumulative infiltration, $I_{3 D}$, model (QEI) for disc infiltrometer measurements corresponding to a zero water pressure head imposed at the soil surface (i.e., saturated conditions) can be described as follows (Haverkamp et al., 1994; Smettem et al. 1994):

$I_{3 D}=I_{1 D}+A t$

$A=\frac{\gamma S^{2}}{r_{d}\left(\theta_{s}-\theta_{i}\right)}$

where $t$ is time (T), $r_{d}$ is the radius of the disc $(\mathrm{L}), S$ is the sorptivity $\left(\mathrm{L} \mathrm{T}^{-0.5}\right)$, and $\gamma$ is a proportionality constant that accounts for the correction of the wetting front shape (Smettem et al., 1994). The $A$ parameter, as originally defined by Lassabatere et al. (2006), quantifies the capillarity-driven lateral water flux (Lassabatere et al., 2006); and $I_{1 D}$ denotes the $1 \mathrm{D}$ 
cumulative infiltration curve that can be modeled using the QEI formulation developed by

$$
\frac{2\left(K_{S}-K_{i}\right)^{2}}{S^{2}} t=\frac{2}{1-\beta} \frac{\left(K_{S}-K_{i}\right)\left(I_{1 D}-K_{i} t\right)}{S^{2}}-\frac{1}{1-\beta} \ln \left[\frac{1}{\beta} \exp \left(2 \beta\left(K_{S}-K_{i}\right)\left(I_{1 D}-K_{i} t\right) / S^{2}\right)+\frac{\beta-1}{\beta}\right]
$$

where $K_{s}$ and $K_{i}\left(\mathrm{~L} \mathrm{~T}^{-1}\right)$ are the hydraulic conductivity values corresponding to saturation, $\theta_{s}$, and initial, $\theta_{i}$, volumetric water content $\left(\mathrm{L}^{3} \mathrm{~L}^{-3}\right)$, respectively, and $\beta$ is the integral shape parameter. For regular working conditions, $\beta$ varies between 0.6 and 1.7 (Lassabatere et al., 2009) and $\gamma$ between 0.6 and 0.8 (Haverkamp et al., 1994).

The cumulative 3D infiltration curve can be also approximated with power series in $t^{1 / 2}$ (Fig.

$$
I_{3 D}(t)=c_{1} t^{\frac{1}{2}}+c_{2} t+c_{3} t^{\frac{3}{2}}+c_{4} t^{2}+c_{5} t^{\frac{5}{2}}+\cdots
$$

where $c_{i}\left(\mathrm{~L} \mathrm{~T}^{-\mathrm{i} / 2}\right)$ are coefficients that depend on the soil hydraulic properties and the initial conditions. The application of Taylor series to the 3D QEI up to fourth order in powers of $t^{1 / 2}$ results in the following 4T approximation (Moret-Fernández et al., 2020):

154 Given that we have four unknown parameters $\left(S, K_{s}, \beta\right.$ and $\left.A\right)$, on one hand, and that four coefficients $\left(c_{i}\right)_{i \in\{1 . .4\}}$ are involved in the $4 \mathrm{~T}$ approximate expansion, on the other, the inverse analysis can potentially determine the four unknowns. However, Moret-Fernández et al. (2020) demonstrated that the $A$ and $\beta$ parameters need to be fixed a priori for the case of water infiltration curve measured with the addition of a contact sand layer (such addition aims to improve the contact between the infiltration device and the soil). Given that inverting infiltration data for soil layered profile remains tricky, in the following, we defined a new method to analyze soilfor layered profiles. 


\subsection{Sequential infiltration analysis (SIA) and soil surface layer thickness estimate}

164

165

Using both QEI and 4T models, the new procedure involves the analysis of a sequence of increasing time series from the cumulative infiltration data. The SIA procedure estimates $S$ and $K_{s}$ by fitting QEI or 4T to increasing time series and computes the RMSE as a function of the number of samples. The optimal infiltration time, $t_{o}$, is identified by the minimum RMSE, and its corresponding inversion provides the estimates of $K_{s}$ and $S$. A total of 30 increasing times ranged from 50s to the total available infiltration data were considered. The inverse analysis with 4T (Eq. 7) was performed using a nonlinear (weighted) least-square method that incorporates the Levenberg-Marquardt optimization algorithm. The procedure was implemented into a function that returns a vector of (weighted) residuals whose sum square is minimized (More, 1978; Bates and Watts, 1988; Bates and Chambers, 1992). To this end, the $\mathrm{R}$ ( $\mathrm{R}$ version 3.5.0. The R Foundation for Statistical Computing) software was employed. For the QEI model, the global inverse analysis proposed by Latorre et al. (2015) was used. In this case, $S$ and $K_{s}$ were estimated by minimizing an objective function that represents the difference between the implicit model (Eq. 1) and the experimental cumulative infiltration data. To this end, a brute-force search (Horst and Romeijn, 2002) was employed, enumerating all possible candidates of the hydraulic parameters to a certain precision and selecting the best result. In all cases, $\gamma$ and $\beta$ values were fixed at their recommended values, 0.75 and 0.6 respectively.

The thickness of the soil surface layer was defined as the position of the wetting front advance $(W F A)$ at time $t_{o}$. The position of the wetting front was calculated as (Lassabatere et al., 2009):

$$
W F A=\frac{I_{1 D}\left(t_{0}\right)}{\theta_{S}-\theta_{i}}
$$


where $I_{1 D}\left(t_{0}\right)$ is calculated according to:

187

$I_{1 D}\left(t_{0}\right)=S t_{0}^{\frac{1}{2}}+\left(\frac{2-\beta}{3} K_{S}\right) t_{0}+\frac{K_{S}^{2}}{9 S}\left(\beta^{2}-\beta+1\right) t_{0}^{\frac{3}{2}}+2(\beta-2)(\beta 1) \frac{(1-2 \beta)}{135} \frac{K_{s}^{3}}{S^{2}} t_{0}^{2}$

using the previously optimized $K_{s}, S$ and $\beta=0.6$.

\section{MATERIAL AND METHODS}

\subsection{Validation of SIA method with synthetic soils (numerically generated data)}

The infiltration curves were simulated with HYDRUS-3D model (Šimunek et al., 1999).

The van Genuchten (1980) model was selected for water retention curves and the Mualem's model (1976) for the unsaturated hydraulic conductivity defined for sandyloam, loam and silt $\mathrm{cm}$ in radius and $25 \mathrm{~cm}$ depth), covering the axisymmetric plane with a $2 \mathrm{D}$ rectangular mesh of 100 x 900 cells. A disc infiltrometer of $10 \mathrm{~cm}$ in radius was represented by a fixed water pressure boundary with a value of $0 \mathrm{~cm}$. A null pressure head was considered as bottom boundary. The initial soil water content corresponded to its residual water content. The synthetic data was computed for $2000 \mathrm{~s}$, which corresponds to a regular experimental infiltration. In addition, we checked that this time was enough for the wetting front did not reach the lower layer. No contact sand layer was defined. More details about the cumulative infiltration curves generation can be found in Latorre et al. (2015). The simulations (Fig. 2) were performed on a homogeneous loam (L) soil and layered soil profiles consisting on a 1 , 2, and $3 \mathrm{~cm}$ thickness loam soil followed by a sandy loam (L-SL) or silt (L-Si) synthetic soil, respectively. The $\theta_{s}$ and $\theta_{i}$ needed to estimate the soil hydraulic parameters are summarized in Table 1. The application of the SIA method leads to the results reported in Table 2 and that will be discussed in the Results section. 


\subsection{Laboratory experiments}

211

Five laboratory infiltration experiments were conducted on different soil columns. The first experiments consisted on three $15 \mathrm{~cm}$ depth and $30 \mathrm{~cm}$ diameter soil columns homogeneously packed with sand (80 $\mu \mathrm{m}$ mean size particle), 2-mm sieved loam $(28,47,25$ and $1.2 \%$ of sand, silt, clay and organic carbon, respectively) and loam clay soils (20, 50, 30 and $2.0 \%$ of sand, silt, clay and organic carbon, respectively). The remaining experiments consisted on 30 $\mathrm{cm}$ diameter columns made with a $3 \mathrm{~cm}$ thickness upper layer of sand and loam soil, followed by a $5 \mathrm{~cm}$ thickness clay loam layer (Fig. 3).

An infiltration curve was measured in each soil column using a $10 \mathrm{~cm}$ diameter Perroux and White (1988) model tension disc infiltrometer. All the infiltration experiments are considered to be $3 \mathrm{D}$ with no impact of the edges of the columns on the lateral expansion of the infiltration bulb. All measurements were performed at soil saturation conditions at surface. The water infiltration was monitored with $\pm 35.2 \mathrm{~cm}$ differential pressure transducer (Microswitch, Honeywell) at $1 \mathrm{~s}$ of time interval. Infiltration measurements continued between 60 seconds and $1400 \mathrm{~s}$. The initial and saturated soil water contents of the upper layer were measured with the core method (Grossman and Reinsch, 2002). Similarly, as described in the previous section, $S, K_{s}$ and $t_{o}$ were estimated with the SIA procedure using both $4 \mathrm{~T}$ and QEI models. A constant $\beta$ and $\gamma$ equal to 0.6 and 0.75 together with the actual disc radius and the measured $\Delta \theta$ (Table 3) were employed. The RMSE and the WFAs were calculated as described in the previous section. Negative $K_{s}$ obtained from the inverse analysis were omitted and fixed to $10^{-5} \mathrm{~mm} \mathrm{~s}^{-1}$. 
The infiltration measurements were performed on agro-pastoral fields located in the municipality of Mediana de Aragón (M1) $\left(41^{\circ} 25^{\prime} \mathrm{N}, 0^{\circ} 44^{\prime} \mathrm{W}\right)$, in the Zaragoza province of Aragón (NE Spain). Average annual temperature and precipitation are $14.9^{\circ} \mathrm{C}$ and $350 \mathrm{~mm}$ $\mathrm{yr}^{-1}$, respectively. The lithology in the area is mainly gypsum outcrops. Soils are Leptosols in the hills and Gypsisols in the flat-bottomed valleys (Navas, 1991). These are poorly developed soils, with a sandy loam to loam texture, high gypsum (between 680 and $940 \mathrm{~g} \mathrm{~kg}^{-1}$ ) and low organic matter (between 9 to $48 \mathrm{~g} \mathrm{~kg}^{-1}$ ) contents (Navas, 1991). Field infiltrations were performed on bare (R1) and soils with plants (R2) in fields with soil with low (L) and medium (M) grazing intensity.

A $50 \mathrm{~mm}$ in diameter and $50 \mathrm{~mm}$ in height undisturbed soil cores were sampled close to the infiltration points. The $\theta_{s}$ was measured by saturating the soil core, and subsequently drying it at $50{ }^{\circ} \mathrm{C}$ during $48 \mathrm{~h}$. The initial volumetric water content $\left(\theta_{i}\right)$ was measured with a DeltaT water content probe. One replication for $\theta_{s}$ and $\theta_{i}$ was performed per sampling site. A $10 \mathrm{~cm}$ diameter disc infiltrometer was employed. A thin layer $(<1 \mathrm{~cm}$ thick $)$ of commercial sand (80-160 $\mu \mathrm{m}$ grain size) was placed between base disc and soil surface. The duration of the experiments varied between 500 and 1800 s, depending on the time needed to reach steady state infiltration conditions. A total of 20 cumulative infiltration curves were recorded. The influence of the contact sand layer $\left(t_{\text {sand }}\right)$ on $K_{s}$ and $S$ estimates was removed using the procedure developed by Latorre et al. (2015). This consists of a layered flow model that assumes that water does not infiltrate into the soil until the sand layer is completely saturated. The sand effect is considered as a gap, in time and volume, before water infiltrates into the soil. The contact sand layer effect is removed by finding the sand infiltration time (and its corresponding water volume) and shifting the experimental data to the origin. The maximum infiltration time due to the sand wetting layer was fixed to $10 \mathrm{~s}$. Consequently, for modeling 
with the SIA method, we no longer considered the sandy layer. Only the soil layering, if any, is expected to have an effect on the cumulative infiltration curves.

The SIA method was then used, as described for the synthetic soils analysis, to provide $S$, $K_{s}, t_{o}$, RMSE and WFA. Both 4T and QEI models were considered for the application of the SIA method on the field measurements.

\section{RESULTS AND DISCUSSION}

\subsection{Results for the synthetic soils (numerically generated data)}

Except for the first infiltration times, $S$ and $K_{s}$ estimates for the homogeneous loam soil (L) using 4T were constant along the whole duration of the experiment (Fig. 4). The initial divergences could be attributed to the large tension difference at the beginning of the experiment, which changes from $-10^{-3}$ to $-10^{7} \mathrm{~cm}$, and affects the numerical stability of the simulated cumulative infiltrations. Apart from this initial variation, the estimates remain constant along the experiment. This result indicates that, under homogeneous soil conditions, the considered infiltration time does not affect the predictions of the hydraulic parameters. Meanwhile, a slight decrease of RMSE was noticed with increasing time for the homogeneous synthetic loam column. This is due to the fact that the difference between the synthetic and simulated curves is divided by the total number of data-points. In addition, the RMSE change with increasing analyzed time resulted in an indicator of the soil heterogeneity, with no significant variations in the absence of soil layering. The RMSE represents the difference between the measured data and the theoretical curve, which is consistent with the hypothesis of a homogeneous soil. Consequently, the sudden increase of the RMSE is expected in the 
presence of soil layering from the time when the infiltration bulb reaches the layers interface and both curves (experimental and theoretical) begin to differ.

In heterogeneous or layered soil profiles, the RMSE increased at the time $\left(t_{o}\right)$ when the infiltration bulb reaches the lower soil layer (Fig. 4b). From time $t_{o}, S$ and $K_{s}$ started to deviate from their theoretical values (Fig. $4 \mathrm{c}$ and d). Thus, these results indicate that the SIA method using 4T detects the soil heterogeneity and identifies the maximum time $\left(t_{o}\right)$ to be considered for accurate estimations of $S$ and $K_{s}$ of the upper soil layer. In contrast, erroneous hydraulic properties were reported when infiltration times larger than $t_{o}$ are employed (Fig.4c and d). For example, this is the case of the $\mathrm{L}_{1 \mathrm{~cm}}+\mathrm{Si}$ soil, where long time analysis resulted in smaller $K_{s}$ values. In this case, the significant decrease of $K_{s}$ from $t_{o}$, should be attributed to the extraconcavity of the infiltration curve promoted by the less permeable deeper soil layer (Di Prima et al., 2018), which forces the model to reduce $K_{s}$ to minimum threshold of $10^{-5} \mathrm{~mm} \mathrm{~s}^{-1}$ defined in the optimization. For the $\mathrm{L}_{1 \mathrm{~cm}}+\mathrm{SL}$ synthetic soil, erroneous $K_{s}$ estimates would be also obtained if, for instance, long-time infiltration values were considered. In this respect, the extra-convexity promoted by the more permeable deeper soil layer, makes $K_{s}$ decreasing to the minimum threshold of $10^{-5} \mathrm{~mm} \mathrm{~s}^{-1}$ just after $t_{o}$, to later stabilize $K_{s}$ at a value close that defined for SL (Table 1). These results indicate that $K_{s}$ evolution from $t_{o}$ contains valuable information about the permeability of the deeper soil layer. In conclusion, these results indicate that the infiltration time is an important factor to estimate the soil hydraulic properties of heterogeneous soil profiles. The SIA method using the 4T model was an efficient tool to detect soil homogeneity and to estimate $S$ and $K_{s}$ from the upper layer of heterogeneous soils.

Overall, good estimates of soil hydraulic properties were obtained when the SIA method, using either 4T or QEI, was applied to the homogeneous synthetic loam soil (Table 2 versus Table 1). In this case, the relative difference between theoretical and the optimized $S$ and $K_{s}$ 
( $K_{s}$ in $\log$ scale) were $0.45 \%$ and $3.17 \%$, respectively. Similar results were reported by Latorre et al. (2015) and Moret-Fernández et al. (2020). Except for the synthetic soil profiles with the thinnest top soil layer $\left(\mathrm{L}_{1 \mathrm{~cm}}+\mathrm{SL}\right.$ and $\left.\mathrm{L}_{1 \mathrm{~cm}}+\mathrm{Si}\right)$, the $S$ and $K_{s}$ estimates with QEI and $4 \mathrm{~T}$ also agreed with their theoretical values (Table 2 versus Table 1). These results indicate that accurate estimations of $S$ and $K_{s}$ require a minimum thickness of soil depth. The similarity of the estimations using the QEI and 4T expansion in heterogeneous profiles (Table 2) corroborates the 4T expansion was accurate enough for a proper estimation of the soil hydraulic properties. This is an interesting result since the complexity of the Latorre et al. (2015) procedure may restrict its use when the SIA method is applied on a large dataset of infiltration measurements. This problem, however, vanishes using the $4 \mathrm{~T}$ model, for which the simpler equation allows fast and affordable analyses.

The numerical results also show that the prediction of the thickness of the upper soil layer is quite accurate. Indeed, the calculated wetting front advance (WFA), were significantly correlated to the real values of the top layer thickness $\left(y=0.94 x+0.36, R^{2}=0.97, p<0.0001\right)$ (Table 2). These results indicate that the thickness of the upper soil layer can be estimated from the sequential analysis of the cumulative infiltration curve, using both QEI and 4T models.

\subsection{Laboratory experiments}

The soil hydraulic properties estimated in the laboratory soil columns are summarized in Table 3. As observed in synthetic homogenous soil (Fig. 4a), the decrease of RMSE with time observed in the uniform loam soil is also present in the uniform laboratory loam (Fig. 5a). The soil uniformity is also corroborated by the almost constant $K_{S}$ and $S$ values estimated along 
the whole infiltration time. The WFA calculated for the loam and clay loam soils (Table 3) were close to the $4.2-4.4 \mathrm{~cm}$ thickness of the wetted soil bulb measured in both soils at the end of the experiment.

A different behavior was observed in the stratified soil columns. The minimum RMSE found with the SIA method indicated a change of soil layer at time $t_{o}$, corresponding to the minimum RMSE value (Fig. $5 \mathrm{~b}$ and c). The smaller $t_{o}$ observed in the sand+clay loam (S+CL) column (Fig. 5c) may be related to the significant higher $K_{s}$ and $S$ of the sand (Table 3), which accelerated the infiltration that reaches the lower layer in less time. However, although the two columns presented an absolute minimum of the RMSE, the $K_{s}$ behavior after time $t_{o}$ was different in the two experiments. The large variability of $K_{s}$ around its optimal value observed in loam soil+clay loam (L+CL) column (Fig. 5b) indicates that the model cannot fit the experimental curve, probably due to the extra concavity observed at large times. The change of soil layer, however, was more evident in the S+CL profile (Fig. 5c), where much contrasted $K_{s}$ and $S$ values were obtained (Table 3). In this case, the smaller $K_{s}$ and $S$ of the clay loam soil generated an infiltration curve with a shift in its slope and shape, and with a significant decrease in $K_{s}$ with time.

Overall, the similarity of $K_{s}$ and $S$ estimates between the homogeneous loam and sand columns, on one hand, and the layered profiles, on the other, (Table 3), indicates that the method was robust and pointed at accurate estimates of the hydraulic properties in all the cases. Overall, the thickness of the upper soil layer predicted from WFA values was close to their actual value (Table 3). As observed in the synthetic soils, these results indicate the SIA method allowed estimating the thickness of the upper soil layer. The robust relationship between $K_{s}$ and $S$ estimates obtained with QEI and 4T models $\left(\mathrm{y}=1.013 \mathrm{x}+0.022 ; \mathrm{R}^{2}=\right.$ 
0.9091; $\mathrm{p}<0.0001)$, is in line with previous results and indicates that $4 \mathrm{~T}$ model is accurate to estimate the soil hydraulic properties.

\subsection{Field measurements}

Overall, the field soils presented a sandy loam texture, high amount of gypsum (73\%) and low organic matter content $(1.66 \%)$. A great variability of types and shapes of infiltration curves was observed from field experiments (Fig. 6). Given the different types of cumulative infiltration curves described by Angulo-Jaramillo et al. (2019), four main types were analyzed: (i) a regular (Fig. 7a), (ii) extra-concavity (Fig. 7b), (iii) double-slope infiltration curve previously checked that it was affected by water repellency phenomena (Fig. 7c), and (iv) infiltration showing some irregularities at early times (Fig. 7d).

In the first case (M1M2R2, Fig. 7a), a standard curve corresponding to a homogeneous soil, where the RMSE decreased along all the experiment (>600 s), with its corresponding estimates reported in Table 4. Other indicators corroborating the homogeneity of this soil were the stability of $S$ and $K_{s}$ estimates and the almost constant time for the contact sand layer, $t_{\text {sand. }}$. These results suggest that the soil profile at the place of this infiltration curve was homogeneous. The thickness of the corresponding soil layer was $4.3 \mathrm{~cm}$ (Table 4).

In the second example (M1L5R1, Fig. 7b), although a preliminary visual analysis might suggest a behavior similar to the previous curve, the sequential analysis evidenced the existence of a non-uniform soil profile within the measured infiltration time. The decreasing behavior of the infiltration rate, which corresponds to a kind of extra-concavity defined by Angulo-Jaramillo et al. (2019), was similar to that observed in the L1cm+Si synthetic soil (Fig. 4b) and also in the stratified laboratory soil columns (Fig. 5b and c). The minimum 
RMSE was located around $170 \mathrm{~s}\left(t_{o}\right)$, time from which the RMSE increased to the end of the infiltration. Other indicator of the existence of a layered profile was the decrease of $K_{s}$ and the large variation of $t_{\text {sand }}$ from $t_{o}$. This large $t_{\text {sand }}$ variation is due to the model had to adapt the $t_{\text {sand }}$ value to find the best fitting for the heterogeneous profile. On the other hand, the decrease of $K_{s}$ over time would indicate that the profile presented a less permeable deeper layer (Di Prima et al., 2018). Although less evident, these changes were also manifested in $S$, whose values kept almost constant until $t_{o}(170 \mathrm{~s})$ before increasing. In this case, the thickness of the top soil layer was $1.4 \mathrm{~cm}$ (Table 4). Thus, the sequential analysis of the infiltration curve suggested the existence of a heterogeneous profile with a less permeable deeper layer.

A different behavior was depicted in Figure 7c (M1L3R1), where an inflection point was observed around $150 \mathrm{~s}$. This behavior was due to water repellence phenomenon (MoretFernández et al., 2019), as previously experimentally checked with the water drop penetration time (WDPT) test (Watson and Letey, 1970). When water infiltrates into hydrophobic soils, the water advance during the early phase of wetting is impeded owing to hydrophobic surface films on soil particles (Jarvis et al., 2008). However, once the hydrophobic layer is overcome $\left(t_{o}\right)$, the infiltration rise promoted a significant increase of RMSE and $K_{s}$, and a decrease of $S$. An important increase of $t_{\text {sand }}$ was also observed just after the inflection point. Although water repellency, and hence the inflection point, can be visually detected (Angulo-Jaramillo et al., 2019), the minimum RMSE located with the SIA procedure allowed a more objective determination of $t_{o}$ and, hence, more accurate estimates of $S$ and $K_{s}$. The average thickness of the top soil layer measured from $W F A$ was around $1.2 \mathrm{~cm}$ (Table 4).

In the last example (M1M2R1, Fig. 7d), a curve with an unclear behavior is presented. In this case, if the determination of $t_{o}$ is only based on the absolute RMSE minimum, a $t_{o}$ around $210 \mathrm{~s}$ was obtained (discontinuous vertical line). However, a more detailed analysis indicated that after the absolute RMSE minimum there is another local minimum that coincides with 
more stable $t_{\text {sand }}, S$ and $K_{s}$ values. Since the dispersion of all variables with time was relatively small, in this case we would suggest omitting the initial times (grey points in Fig. 5d) and analyze the remaining infiltration section. In this case, $t_{o}$ increased up to $680 \mathrm{~s}$ (Table 4 ) and the corresponding WFA was about $3.4 \mathrm{~cm}$. All these examples demonstrated that the SIA method can be applied to real experimental data and should be considered when accurate estimates of hydraulic properties are required.

Overall, similar $S, K_{s}, t_{o}, \alpha, n$ and $W F A$ values were obtained with both QEI and 4T models (Table 4). The robust relationships between the hydraulic parameters estimated with both models (Table 5) indicates that hydraulic properties could be indistinctly estimated with QEI or 4T models. The small differences between both models could be explained by the different time increment employed to remove the effect of the contact sand layer (Latorre et al., 2015): 0.5 vs. $0.1 \mathrm{~s}$ for QEI and 4T, respectively. Preliminary analyses of synthetic soils with sand layer using the same time increment $(0.1 \mathrm{~s})$ confirmed not significant differences between QEI and $4 \mathrm{~T}$ only attributed to the different employed optimization algorithms. The larger time interval used in QEI is the result of a compromise between computation time and accuracy. That is to say, shorted time intervals would result in excessively long calculation times. However, the simpler and faster analysis of the $4 \mathrm{~T}$ model allowed reducing this time interval, which might result in better estimates of the hydraulic properties. These results suggest that the $4 \mathrm{~T}$ expansion is a robust alternative to estimate the soil hydraulic properties from the inverse analysis of a cumulative infiltration curve within a large range of infiltration times.

The $S$ and $K_{s}$ estimated from the measured infiltration curves ranged between 0.07 to 0.60 $\mathrm{mm} \mathrm{s}^{-0.5}$ and $1.810^{-3}$ to $3.7210^{-2} \mathrm{~mm} \mathrm{~s}^{-1}$, respectively. Over the 20 experimental infiltrations, only 3 measurements presented a $t_{o}$ equal to the total measured infiltration time $(\approx 600 \mathrm{~s}) ; 25$ $\%$ of the analyzed curves presented $t_{o}>400 \mathrm{~s}$ and $200<t_{o}<400$, respectively, and $50 \%$ a $t_{o}$ $<200 \mathrm{~s}$. These results would indicate that for the most cases the hydraulic properties were 
422 estimated from short to medium infiltration times. For the $70 \%$ of the studied soils, the estimated upper soil layer was thinner than $2 \mathrm{~cm}$, and only three soils presented a uniform upper layer wider than $4 \mathrm{~cm}$. These results suggest that, overall, the analyzed soils presented a thin upper layer, which could probably correspond with the soil surface crust.

\section{5}

\section{. CONCLUSIONS}

This work presents a procedure to analyze the infiltration curves measured on layered soil profiles. This new method, referred as SIA, Sequential Infiltration Analysis, consists of analyzing infiltration curves at increasing time intervals, and calculating the corresponding $K_{s}, S$ and the RMSE characterizing the quality of the fit. To this end, both QEI and 4T models were employed. A procedure to estimate the wetting front advance (WFA) or the thickness of the upper uniform soil layer from the infiltration analysis was also presented. The procedure, which was applied on synthetic layered profiles and experimental soils, showed that erroneous estimates of $K_{s}$ and $S$ were obtained when the inverse analysis was applied to the whole infiltration curve obtained for heterogeneous profiles. This limitation, however, vanished using the SIA procedure, which allowed satisfactory estimates of $t_{o}, K_{s}, S$ and the corresponding WFA for very different types of infiltration curves. However, because the SIA method sequentially analyzes the series of infiltrations, results only correspond to the upper soil layer, which can be considered homogeneous. This hypothesis implies a limitation of the method when the thickness of the upper layer is very thin. On the other hand, since the results also show that some of the properties of the deepest soil layers are also contained in the infiltration curve, it opens the possibility to advance in the method improvement to obtain 
446 additional information of the total soil profile from the analysis of the complete infiltration

447 curve. In most experimental soils, only short to medium infiltration times could be analyzed,

448 and the thickness of the upper homogeneous soil layer ranged between 1 and $5 \mathrm{~cm}$. In 449 conclusion, these results showed that great care must be taken when calculating the soil 450 hydraulic properties from the inversion of the measured infiltration curves, questioning the 451 possibility that anomalous curves cannot be analyzed accurately. On the other hand, although 452 similar results were obtained with both QEI and 4T models, the simpler and faster analysis 453 allowed by 4T suggests that this expansion can be a robust alternative to be implemented in 454 the SIA method for the estimation of the $K_{s}$ and $S$ of the top layer of layered soil profiles

\section{Acknowledgments}

457 This research was supported by the Ministerio de Economía, Industria y Competitividad, 458 project PROPAST (CGL2016-80783-R) and ASBIO (PGC2018-094332-B-100), the 459 International Emerging Action (IEA) (PICS08250), and in part supported by the European 460 Regional Development Fund (ERDF) and the Italian Ministry of Education, University and 461 Research (MIUR) through the "Programma Operativo Nazionale (PON) Ricerca e 462 Innovazione 2014-2020 (Linea 1 - Mobilità dei ricercatori, AIM1853149, CUP: 463 J54I18000120001). The authors are grateful to Área de Informática Científica of SGAI 464 (CSIC) for their technical support in the numerical analysis and to R. Gracia and M.J. Salvador 465 for technical help in several aspects of this study.

\section{References}


Angulo-Jaramillo, R., Bagarello, V., Di Prima, S., Gosset, A., Iovino, M., Lassabatere, L. 2019. Beerkan Estimation of Soil Transfer parameters (BEST) across soils and scales. Journal of Hydrology 576, 239-261.

Angulo-Jaramillo, R., Vandervaere, J.P., Roulier, S., Thony, J.L., Gaudet, J.P., Vauclin, M. 2000. Field measurement of soil surface hydraulic properties by disc and ring infiltrometers. A review and recent developments. Soil Tillage Research 55, 1-29.

Ankeny, M.D., Ahmed, M., Kaspar, T.C., Horton, R., 1991. Simple field method determining unsaturated hydraulic conductivity. Soil Sci. Soc. Am. J. 55, 467- 470.

Bates, D. M., Watts, D. G. 1988 Nonlinear Regression Analysis and Its Applications, Wiley.

Bates, D. M., Chambers, J. M. 1992 Nonlinear models. Chapter 10 of Statistical Models in S eds J. M. Chambers and T. J. Hastie, Wadsworth \& Brooks/Cole.

Beatty, S.M., Smith, J.E., 2013. Dynamic soil water repellency and infiltration in postwildfire soils. Geoderma 192, 160-172.

Carsel, R.F., Parrish, R.S., 1988. Developing joint probability distributions of soil water retention characteristics. Water Resour. Res. 24, 755-769.

Di Prima, S., Concialdi, P., Lassabatere, L., Angulo-Jaramillo, R., Pirastru, M., Cerdà, A., Keesstra, S., 2018. Laboratory testing of Beerkan infiltration experiments for assessing the role of soil sealing on water infiltration. CATENA 167, 373-384.

Fernandez-Galvez, J., Pollacco, J.A.P., Lassabatere, L., Angulo-Jaramillo, R., Carrick, S. 2019. A general Beerkan Estimation of Soil Transfer parameters method predicting hydraulic parameters of any unimodal water retention and hydraulic conductivity 
curves: Application to the Kosugi soil hydraulic model without using particle size distribution data. Advances in Water Resources 129, 118-130.

Grossman, R.B., Reinsch, T.G., 2002. Bulk density and linear extensibility. In: Dane, J.H., Topp, G.C. (Eds.), Methods of Soil Analysis. Part 4. SSSA Book Series No. 5. Soil Science Society of America, Madison, WI.

Fernández-Gálvez, J., Pollacco, J. A. P., Lassabatere, L., Angulo-Jaramillo, R. and Carrick, S. 2019. A general Beerkan Estimation of Soil Transfer parameters method predicting hydraulic parameters of any unimodal water retention and hydraulic conductivity curves: Application to the Kosugi soil hydraulic model without using particle size distribution data, Advances in Water Resources, 129, 118-130, doi:10.1016/j.advwatres.2019.05.005.

Haverkamp, R., Ross, P.J., Smettem, K.R.J., Parlange, J.Y., 1994. Three dimensional analysis of infiltration from the disc infiltrometer. Part 2. Physically based infiltration equation. Water Resour. Res. 2931-2935.

Heanes, D.L., 1984. Determination of total organic-C in soils by an improved chromicacid digestion and spectrophotometric procedure. Commun. Soil Sci. Plant Anal. 15, 11911213.

Horst, R., Romeijn, H.E. (Eds.), 2002. Handbook of Global Optimization, vol. 2.Springer Science \& Business Media.

Iovino, M., Angulo-Jaramillo, R., Bagarello, V., Gerke, H.H., Jabro, J., Lassabatere, L., 2017. Thematic Issue on Soil Water Infiltration. Journal of Hydrology and Hydromechanics 65, 205-208. https://doi.org/10.1515/johh-2017-0036 
Jarvis, N., Etana, A., Stagnitti, F., 2008. Water repellency, near-saturated infiltration and preferential solute transport in a macroporous clay soil. Geoderma 143, 223-230.

Lassabatere, L., Di Prima, S., Angulo-Jaramillo, R., Keesstra, S., Salesa, D., 2019. Beerkan multi-runs for characterizing water infiltration and spatial variability of soil hydraulic properties across scales. Hydrol. Sci. J. 64, 165-178.

Lassabatere, L., Angulo-Jaramillo, R., Soria, J.M., Cuenca, R., Braud, I., Haverkamp, R. 2006. Beerkan estimation of soil transfer parameters though infiltration experiments BEST. Soil Sci. Soc. Am. J. 70, 521.532.

Lassabatere, L., Angulo-Jaramillo, R., Soria-Ugalde, J.M., Simunek, J., Haverkamp, R., 2009. Numerical evaluation of a set of analytical infiltration equations. Water Resour. Res. https://doi.org/10.1029/2009WR007941.

Lassabatere, L., Yilmaz, D., Peyrard, X., Peyneau, P.E., Lenoir, T., Šimůnek, J., AnguloJaramillo, R., 2014. New analytical model for cumulative infiltration into dualpermeability soils. Vadose Zone Journal 13, 1-15. https://doi.org/10.2136/vzj2013.10.0181

Lassabatere, L., Angulo-Jaramillo, R., Goutaland, D., Letellier, L., Gaudet, J.P., Winiarski, T., Delolme, C., 2010. Effect of the settlement of sediments on water infiltration in two urban infiltration basins. Geoderma 316-325. https://doi.org/10.1016/j.geoderma.2010.02.031

Latorre, B., Peña, C., Lassabatere, L., Angulo-Jaramillo, R., Moret-Fernández, D., 2015. Estimate of soil hydraulic properties from disc infiltrometer three-dimensional infiltration curve. Numerical analysis and field application. J. Hydrol. 57, 1-12. 
Latorre, B., Moret-Fernández, D., Lassabatere, L., Rahmati, M., López, M.V., AnguloJaramillo, R., Sorando, R., Comín, F., Jiménez, J.J. 2018. Influence of the $\beta$ parameter of the Haverkamp model on the transient soil water infiltration curve. J. Hydrol. 564, 222-229.

More, J.J. 1978. The Levenberg-Marquardt algorithm: implementation and theory; in Lecture Notes in Mathematics 630: Numerical Analysis, G.A. Watson (Ed.), Springer-Verlag: Berlin, pp. 105-116.

Moret-Fernández, D., Latorre, B., Angulo-Martínez, M. 2017. Comparison of different methods to estimate the soil sorptivity from an upward infiltration curve. Catena 155, 86-92.

Moret-Fernández, D., Latorre, B. 2017. Estimate of the soil water retention curve from the sorptivity and $\beta$ parameter calculated from an upward infiltration experiment. J. Hydrol. 544, 352-362

Moret-Fernández, D., Blanco, N., Martínez-Chueca, V., Bielsa, A. 2013. Malleable disc base for direct infiltration measurements using the tension infiltrometry technique. Hydrol. Proc. 27, 275, 283.

Moret-Fernández, D., Latorre, B., López, M.V., Pueyo, Y., Lassabatere, L., Angulo-Jaramilo, R., Rahmati, M., Tormo, J., Nicolau, J.M. 2020. Three- and four-term approximate expansions of Haverkamp formulation to estimate soil hydraulic properties from disc infiltrometer measurements. Hydrological Processes, DOI: 10.1002/hyp.13966.

Moret-Fernández, D., Latorre, B., Giner, M.L., Ramos, , J, Alados, C.L., Castellano, C., López, M.V., Jimenez, J.J. , Pueyo, Y. 2019. Estimation of the soil hydraulic properties 

from the transient infiltration curve measured on soils affected by water repellency. Catena 178, 298-306

Mualem, Y. 1976. A new model for predicting the hydraulic conductivity of unsaturated porous media. Water Resour. Res. https://doi.org/10.1029/WR012i003p00513.

Navas, A. 1991. The pattern of gypsum transport in the Ebro river network. Catena 18, 45-49.

Parlange, J.Y. 1975. On solving the flow equation in unsaturated flow by optimization: horizontal infiltration. Soil Sci. Soc. Am. J. 39, 415-418.

Perroux, K.M., White, I., 1988. Designs for disc permeameters. Soil Sci. Soc. Am. J. 52, 1205-Philip, J.R., 1957. The theory of infiltration: 4. Sorptivity and algebraic infiltration equations. Soil Sci. 84, 257-264.1215.

Porta J., Lopez-Acebedo M., Rodriguez R. 1986. Tecnicas y experimentos en edafologia. Dep. de Cien-cias del Suelo-ETSIA. Lerida, Spain.

Rahmati, M., Latorre, B., Lassabatere, L., Angulo-Jaramillo, R., Moret-Fernández, D. 2019. The relevance of Philip theory to Haverkamp quasi-exact implicit analytical formulation and its uses to predict soil hydraulic properties. Journal of Hydrology 570, 816-826.

Šimunek, J., Šejna, M., van Genuchten, M.-Th., 1999. The HYDRUS-2D Software Package for Simulating the Two-dimensional Movement of Water, Heat, and Multiple Solutes in Variably-saturated Media. Version 2.0. U.S. Salinity laboratory, Agricultural Research Service, USDA, Riverside, California.

Simunek, J., van Genuchten, M.T., 1996. Estimating unsaturated soil hydraulic properties from tension disc infiltrometer data by numerical inversion. Water Resour. Res. 32, 2683-2696. 
577 Smettem, K., Parlange, J., Ross, P. and Haverkamp, R.: Three-dimensional analysis of 578 infiltration from the disc infiltrometer: 1. A capillary-based theory, Water Resources $579 \quad$ Research, 30(11), 2925-2929.

580

van Genuchten, M.T., 1980. A closed form equation for predicting the hydraulic conductivity 581 of unsaturated soils. Soil Sci. Soc. Am. J. 44, 892-898.

582 Vandervaere, J.-P., Vauclin, M., Elrick, D.E., 2000. Transient flow from tension infiltrometers 583 I. The two-parameter equation. Soil Sci. Soc. Am. J. 64 (4), 1263-1272.

584 Watson, C.L., Letey, J., 1970. Indices for characterizing soil-water repellency based upon 585 contact angle-surface tension relationships. Soil Sci. Soc. Am. J. 34, 841-844. 
Figure 1. Diagram of the considered cumulative infiltration equations, QEI and its 590 corresponding 4T approximation.

591

Figure 2. Schema of the synthetic soil experiments simulated with HYDRUS-3D.

593

594

595

596

597

598

599

600

601

602

603

604

605

606

607

Figure 3. Description of the conducted laboratory experiments using a tension disc infiltrometer.

Figure 4. (a) Cumulative infiltration curves simulated on a homogeneous synthetic loam soil (L) and 1 and $3 \mathrm{~cm}$ loam layer followed by a sandy loam (SL) and silt (Si) layers, and the corresponding temporal evolution of the (b) RMSE, (c) soil sorptivity, $S$, and (c) saturated hydraulic conductivity, $K_{s}$. Vertical lines denote the optimal time, $t_{o}$, corresponding to the minimum RMSE, and horizontal lines in (c) and (d) indicate the theoretical $S$ and $K_{s}$ values.

Figure 5. Measured (Exp) and optimized (Opt) cumulative infiltration curves and temporal evolution of the RMSE, soil sorptivity, $S$, and saturated hydraulic conductivity, $K$ estimated from (a) homogeneous loam soil, (b) $3 \mathrm{~cm}$ thickness loam soil followed by clay loam and (c) $3 \mathrm{~cm}$ thickness sand followed by clay loam columns. Vertical lines 

blue lines indicate the optimal $S$ and $K_{S}$ values, respectively.

610

611 Figure 6. Cumulative infiltration curves measured in field conditions.

612

613 Figure 7. Measured (Exp) and optimized (Opt) cumulative infiltration curves, and temporal evolution of the contact sand layer, $t_{\text {sand }}, \mathrm{RMSE}$, soil sorptivity, $S$, saturated hydraulic conductivity, $K_{s}$, corresponding to the (a) M1M2R2, (b) M1L5R1, (c) M1L3R1 and (d) M1M2R1 sampling points. Vertical lines denote the optimal time, $t_{o}$, of the simulations and horizontal blue and green lines are the corresponding optimal $K_{s}$ and $S$ values. 
621 Table 1. Initial, $\theta_{i}$, residual, $\theta_{r}$, and final,

$622 \theta_{s}$, soil volumetric water contents,

623 sorptivity, $S$ (Eq. 8), saturated hydraulic

624 conductivity, $K_{s}, \alpha$ and $n$ parameters of van

625 Genuchten (1980) model of synthetic

626 sandyloam, loam and silt soils.

\begin{tabular}{lcccccc}
\hline Soil & $\begin{array}{c}\theta_{s} \\
\mathrm{~cm}^{3} \mathrm{~cm}^{-3}\end{array}$ & $\begin{array}{c}\theta_{i}, \theta_{r} \\
\mathrm{~cm}^{3} \mathrm{~cm}^{-3}\end{array}$ & $\begin{array}{c}\alpha \\
\mathrm{mm}^{-3}\end{array}$ & $n$ & $\begin{array}{c}K_{s} \\
\mathrm{~mm} \mathrm{~s}^{-1}\end{array}$ & $\begin{array}{c}S^{*} \\
\mathrm{~mm} \mathrm{~s}^{-0.5}\end{array}$ \\
\hline Sandyloam & 0.41 & 0.065 & 0.75 & 1.89 & $1.2310^{-2}$ & 0.635 \\
Loam & 0.43 & 0.078 & 0.36 & 1.56 & $2.8810^{-3}$ & 0.367 \\
Silt & 0.46 & 0.034 & 0.16 & 1.37 & $6.9410^{-4}$ & 0.238 \\
\hline
\end{tabular}

627

*Moret-Fernández et al. (2017)

628 
Table 2. Soil sorptivity, $S$, saturated hydraulic conductivity, $K_{s}$, optimal time for the best optimization, $t_{o}$, and wetting front advance, WFA, estimated with QEI and 4T expansion for the synthetic soils of Table 1.

\begin{tabular}{|c|c|c|c|c|c|c|c|c|}
\hline \multirow[t]{2}{*}{ Soil } & \multicolumn{4}{|c|}{$Q E I$} & \multicolumn{4}{|c|}{$4 T$} \\
\hline & $S$ & $K_{s}$ & $t_{o}$ & WFA & $S$ & $K_{s}$ & $t_{o}$ & WFA \\
\hline & $\mathrm{mm} \mathrm{s}^{-0.5}$ & $\mathrm{~mm} \mathrm{~s}^{-1}$ & $\mathrm{~s}$ & $\mathrm{~cm}$ & $\mathrm{~mm} \mathrm{~s}^{-0.5}$ & $\mathrm{~mm} \mathrm{~s}^{-1}$ & $\mathrm{~s}$ & $\mathrm{Cm}$ \\
\hline $\mathrm{L}$ & 0.369 & 0.0023 & 1800 & 4.79 & 0.370 & 0.0024 & 1800 & 4.82 \\
\hline $\mathrm{L}_{\mathrm{lcm}}+\mathrm{SL}$ & 0.340 & 0.0035 & 100 & 0.99 & 0.366 & 0.0034 & 100 & 1.06 \\
\hline $\mathrm{L}_{2 \mathrm{~cm}}+\mathrm{SL}$ & 0.370 & 0.0023 & 250 & 1.70 & 0.370 & 0.0024 & 250 & 1.70 \\
\hline $\mathrm{L}_{3 \mathrm{~cm}}+\mathrm{SL}$ & 0.370 & 0.0023 & 600 & 2.68 & 0.370 & 0.0023 & 650 & 2.80 \\
\hline $\mathrm{L}_{\mathrm{lcm}}+\mathrm{Si}$ & 0.370 & 0.0033 & 100 & 1.07 & 0.364 & 0.0033 & 150 & 1.30 \\
\hline $\mathrm{L}_{2 \mathrm{~cm}}+\mathrm{Si}$ & 0.367 & 0.0026 & 300 & 1.86 & 0.368 & 0.0025 & 350 & 2.02 \\
\hline $\mathrm{L}_{3 \mathrm{~cm}}+\mathrm{Si}$ & 0.368 & 0.0023 & 600 & 2.67 & 0.369 & 0.0023 & 700 & 2.89 \\
\hline
\end{tabular}

629

630 
Table 3. Measured initial/residual $\left(\theta_{i} / \theta_{r}\right)$ and saturated volumetric water content $\left(\theta_{s}\right)$ total infiltration time $\left(t_{t}\right)$ and optimum infiltration time $\left(t_{o}\right)$, sorptivity $(S)$ and saturated hydraulic conductivity $\left(K_{s}\right)$, and estimated wetting front advance $(W F A)$ values calculated with QEI and 4T model.

\begin{tabular}{|c|c|c|c|c|c|c|c|c|c|c|c|}
\hline & & & & \multicolumn{4}{|c|}{$Q E I$} & \multicolumn{4}{|c|}{$4 T$} \\
\hline & $\theta_{i} / \theta_{r}$ & $\theta_{s}$ & $t_{\max }$ & $t_{o}$ & $S$ & $K_{s}$ & WFA & $t_{o}$ & $S$ & $K_{s}$ & WFA \\
\hline & $-\mathrm{cm}$ & -3 & 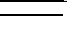 & - & $\mathrm{mm} \mathrm{s}^{-0.5}$ & $\mathrm{~mm} \mathrm{~s}^{-1}$ & $\mathrm{~cm}$ & $\mathrm{~s}$ & $\mathrm{~mm} \mathrm{~s}^{-0.5}$ & $\mathrm{~mm} \mathrm{~s}^{-1}$ & $\mathrm{~cm}$ \\
\hline Sand & 0.03 & 0.390 & 15 & - & - & - & - & 9 & 1.9 & $8.610^{-1}$ & 2.69 \\
\hline Loam & 0.03 & 0.417 & 910 & 866 & 0.51 & $1.710^{-3}$ & 3.98 & 881 & 0.52 & $6.410^{-4}$ & 4.02 \\
\hline Clay loam & 0.02 & 0.470 & 876 & 854 & 0.52 & $9.610^{-4}$ & 3.42 & 839 & 0.53 & $1.610^{-3}$ & 3.48 \\
\hline $3 \mathrm{~cm}$ loam + clay loam & 0.03 & 0.417 & 560 & 415 & 0.52 & $3.510^{-3}$ & 2.83 & 410 & 0.53 & 3. $910^{-4}$ & 2.78 \\
\hline $3 \mathrm{~cm}$ sand + clay loam & 0.03 & 0.390 & 1335 & - & - & - & 3.11 & 9 & 1.05 & $9.610^{-1}$ & 3.11 \\
\hline
\end{tabular}

631

632 
Table 3. Measured initial/residual $\left(\theta_{r} / \theta_{r}\right)$ and saturated volumetric water content $\left(\theta_{s}\right)$ total infiltration time $\left(t_{t}\right)$ and optimum infiltration time $\left(t_{o}\right)$, sorptivity $(S)$ and saturated hydraulic conductivity $\left(K_{s}\right)$ estimated with QEI and $4 \mathrm{~T}$ models from disc infiltrometer measurements.

\begin{tabular}{|c|c|c|c|c|c|c|c|c|c|c|c|}
\hline & \multirow[t]{2}{*}{$\theta_{r} / \theta_{r}$} & \multirow[t]{2}{*}{$\theta_{s}$} & \multirow[t]{2}{*}{$t_{t}$} & \multicolumn{2}{|c|}{$t_{o}$} & \multicolumn{2}{|c|}{$S$} & \multicolumn{2}{|c|}{$K_{s}$} & \multicolumn{2}{|c|}{$W F A$} \\
\hline & & & & QEI & $4 \mathrm{~T}$ & QEI & $4 \mathrm{~T}$ & QEI & $4 \mathrm{~T}$ & QEI & $4 \mathrm{~T}$ \\
\hline & \multicolumn{2}{|c|}{$-\mathrm{cm}^{3} \mathrm{~cm}^{-3}$} & $\longrightarrow$ & - & ; & 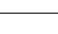 & $\mathrm{n} \mathrm{s}^{-0.5}$ & \multicolumn{2}{|c|}{$\mathrm{mm} \mathrm{s}^{-1}$} & - & \\
\hline M1L1R1 & 0.03 & 0.42 & 960 & 148 & 148 & 0.25 & 0.25 & $1.8010^{-03}$ & $1.5810^{-03}$ & 0.62 & 0.62 \\
\hline M1L1R2 & 0.04 & 0.51 & 899 & 260 & 325 & 0.07 & 0.09 & $1.0010^{-02}$ & $1.0610^{-02}$ & 0.67 & 0.88 \\
\hline M1L2R1 & 0.03 & 0.38 & 837 & 142 & 100 & 0.26 & 0.27 & $2.5710^{-03}$ & $2.7110^{-03}$ & 0.92 & 0.79 \\
\hline M1L2R2 & 0.02 & 0.41 & 779 & 217 & 297 & 0.25 & 0.25 & $1.1710^{-02}$ & $1.1510^{-02}$ & 1.20 & 1.48 \\
\hline M1L3R1 & 0.02 & 0.50 & 743 & 137 & 156 & 0.36 & 0.37 & $1.0710^{-02}$ & $8.9210^{-03}$ & 0.98 & 1.05 \\
\hline M1L3R2 & 0.04 & 0.51 & 898 & 145 & 145 & 0.04 & 0.03 & $5.5010^{-03}$ & $5.3810^{-03}$ & 0.20 & 0.20 \\
\hline M1L4R1 & 0.04 & 0.48 & 866 & 316 & 287 & 0.28 & 0.27 & $2.2910^{-02}$ & $2.3010^{-02}$ & 2.02 & 1.85 \\
\hline M1L4R2 & 0.03 & 0.51 & 857 & 357 & 266 & 0.13 & 0.11 & $1.2010^{-02}$ & $1.1710^{-02}$ & 1.05 & 0.76 \\
\hline M1L5R1 & 0.03 & 0.45 & 720 & 208 & 172 & 0.31 & 0.31 & $1.1910^{-02}$ & $1.2510^{-02}$ & 1.28 & 1.14 \\
\hline M1L5R2 & 0.02 & 0.55 & 648 & 165 & 149 & 0.24 & 0.24 & $1.5510^{-02}$ & $1.5310^{-02}$ & 0.79 & 0.73 \\
\hline M1M1R1 & 0.04 & 0.42 & 842 & 184 & 163 & 0.19 & 0.20 & $1.0710^{-02}$ & $9.1410^{-03}$ & 0.89 & 0.83 \\
\hline M1M1R2 & 0.02 & 0.48 & 597 & 548 & 593 & 0.52 & 0.52 & $2.9510^{-02}$ & $2.8910^{-02}$ & 4.50 & 4.74 \\
\hline M1M2R1 & 0.04 & 0.50 & 907 & 644 & 708 & 0.41 & 0.41 & $1.3310^{-02}$ & $1.3810^{-02}$ & 3.07 & 3.30 \\
\hline M1M2R2 & 0.04 & 0.41 & 727 & 682 & 663 & 0.42 & 0.42 & $1.3810^{-02}$ & $1.3910^{-02}$ & 4.05 & 3.97 \\
\hline M1M3R1 & 0.04 & 0.47 & 774 & 139 & 139 & 0.34 & 0.38 & $2.9510^{-02}$ & $2.5010^{-02}$ & 1.40 & 1.40 \\
\hline M1M3R2 & 0.02 & 0.46 & 837 & 309 & 309 & 0.44 & 0.45 & $9.4410^{-03}$ & $6.5710^{-03}$ & 1.99 & 1.97 \\
\hline M1M4R1 & 0.03 & 0.43 & 777 & 178 & 100 & 0.14 & 0.14 & $4.7910^{-03}$ & $6.5510^{-03}$ & 0.55 & 0.40 \\
\hline M1M4R2 & 0.02 & 0.51 & 582 & 507 & 522 & 0.59 & 0.60 & $2.2910^{-02}$ & $2.2410^{-02}$ & 3.72 & 3.78 \\
\hline M1M5R1 & 0.04 & 0.48 & 751 & 175 & 194 & 0.17 & 0.18 & $2.2910^{-02}$ & $2.1910^{-02}$ & 1.09 & 1.17 \\
\hline M1M5R2 & 0.03 & 0.47 & 826 & 141 & 100 & 0.36 & 0.33 & $3.3110^{-02}$ & $3.7210^{-02}$ & 1.47 & 1.14 \\
\hline
\end{tabular}

633 
$Q E I\left(I_{3 D}, t\right)=0 \quad$ Haverkamp et al. (1994)

Implicit

Taylor series

$$
I_{3 D}(t)=c_{1} t^{\frac{1}{2}}+c_{2} t+c_{3} t^{\frac{3}{2}}+c_{4} t^{2}+\cdots
$$

Explici

Validity range

White et al. (1992)

4T approximation

Moret-Fernández et al. (2020)

Figure 1.

635

636 
Hydrus 3D

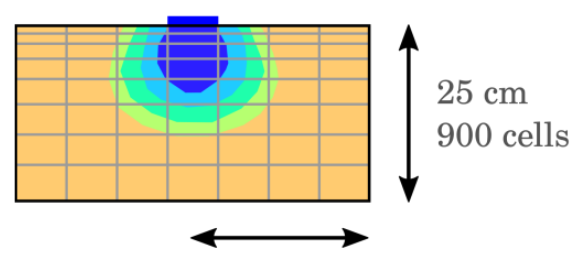

$25 \mathrm{~cm}$

100 cells

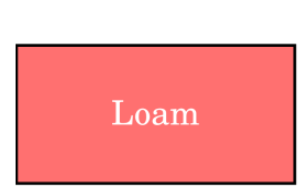

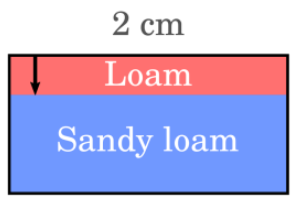

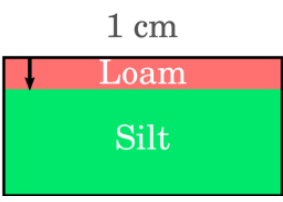

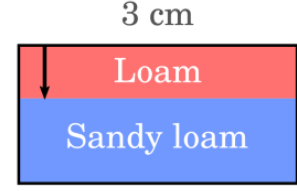

Numerically generated

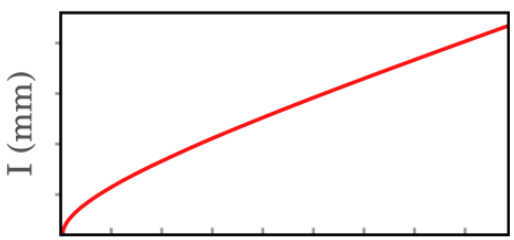

Time (s)

\begin{tabular}{|c|}
\hline Loam \\
Silt \\
\hline
\end{tabular}

Figure 2.

637 


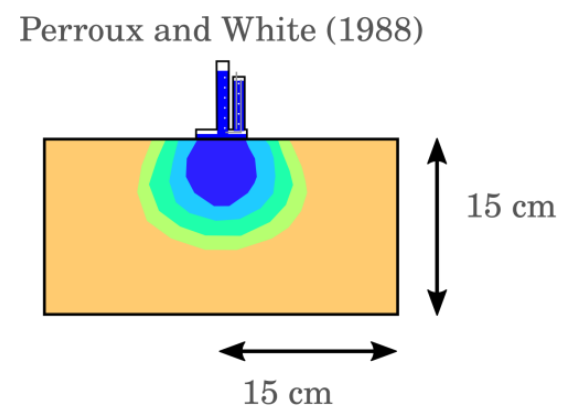

Pressure Transducer measures
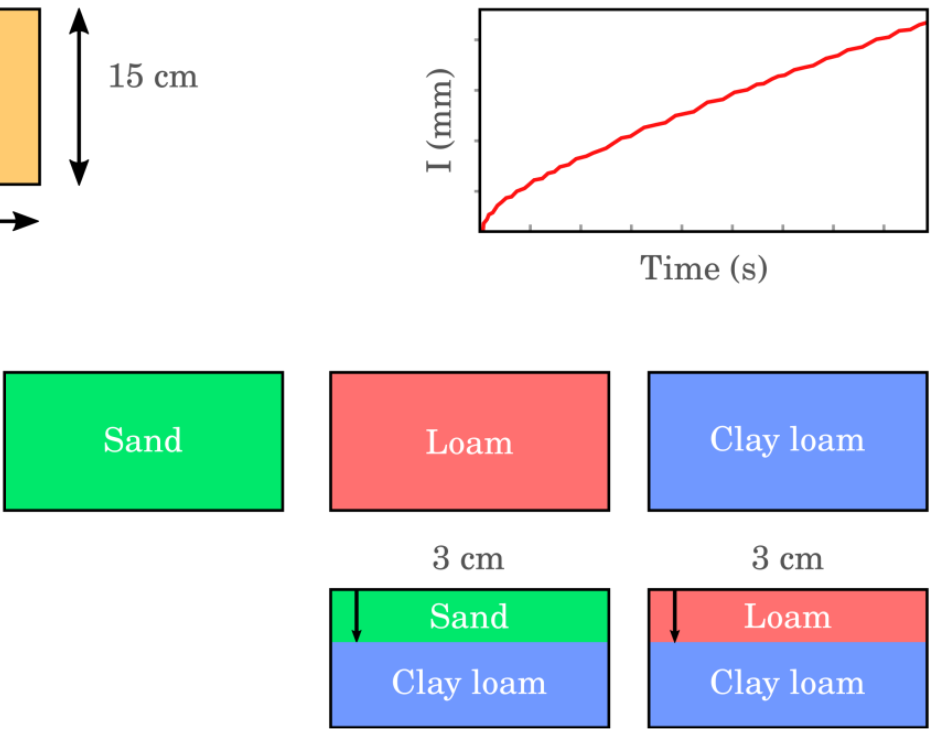

Figure 3.

639

640 


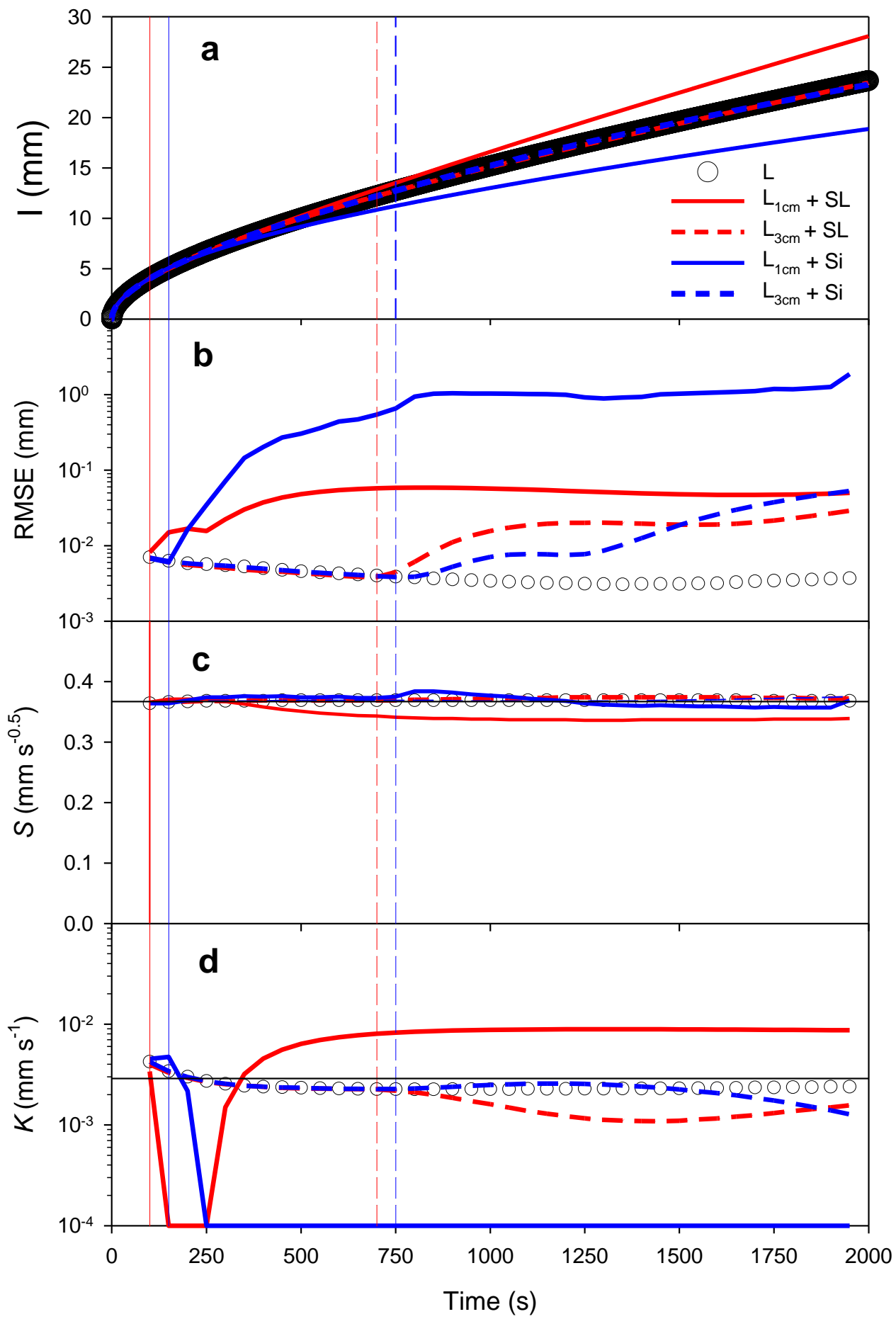

Figure 4. 


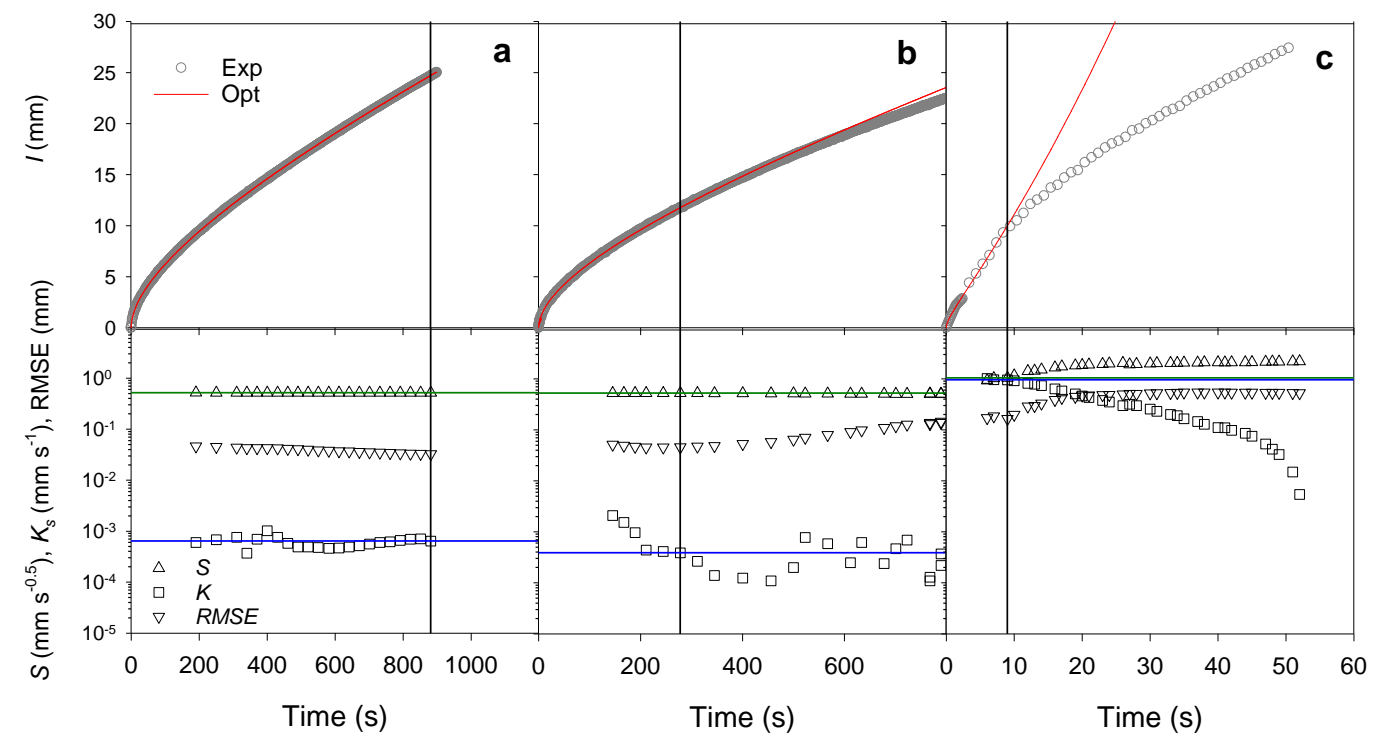

643

Figure 5.

644 


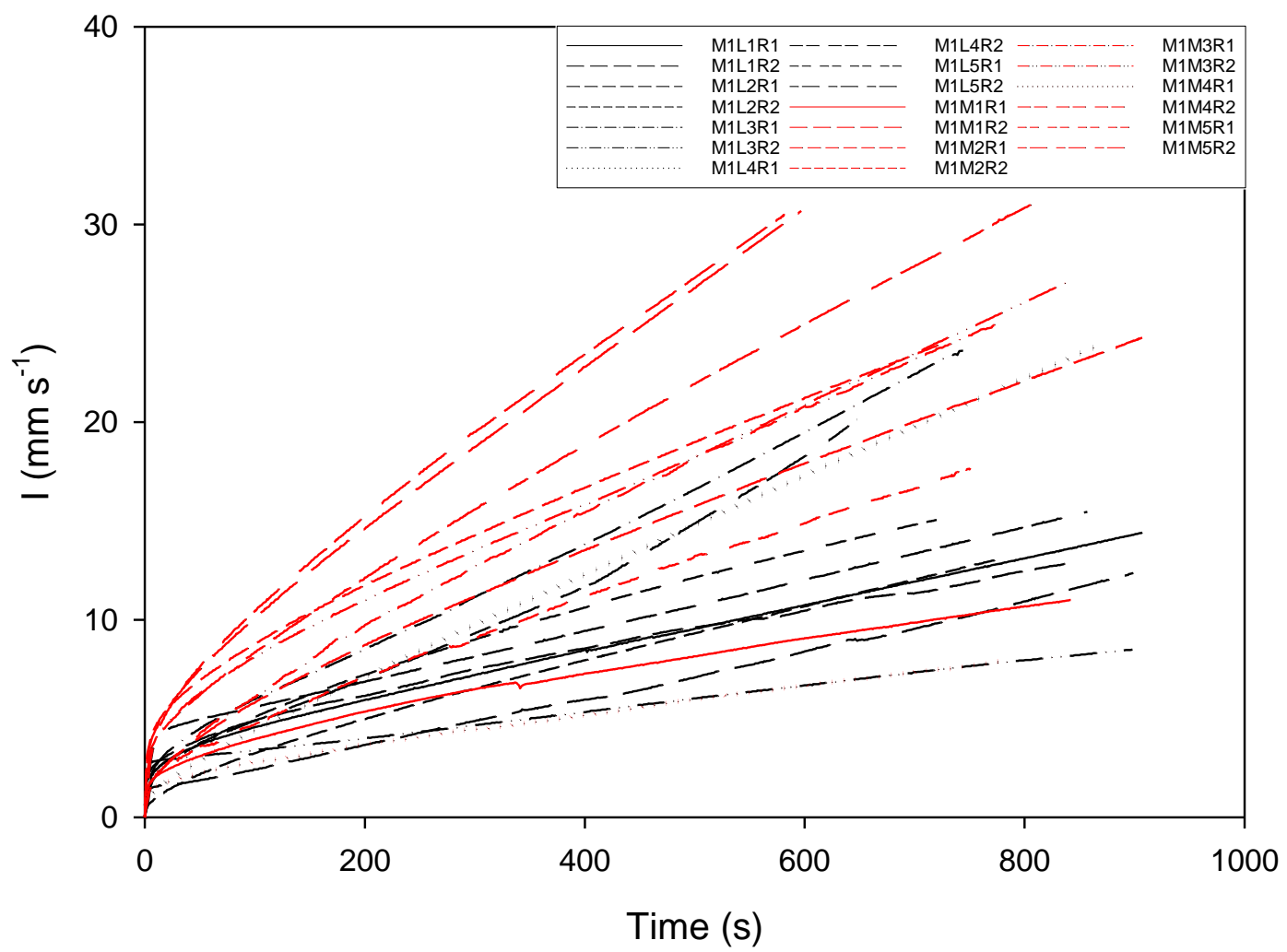

Figure 3.

645

646 


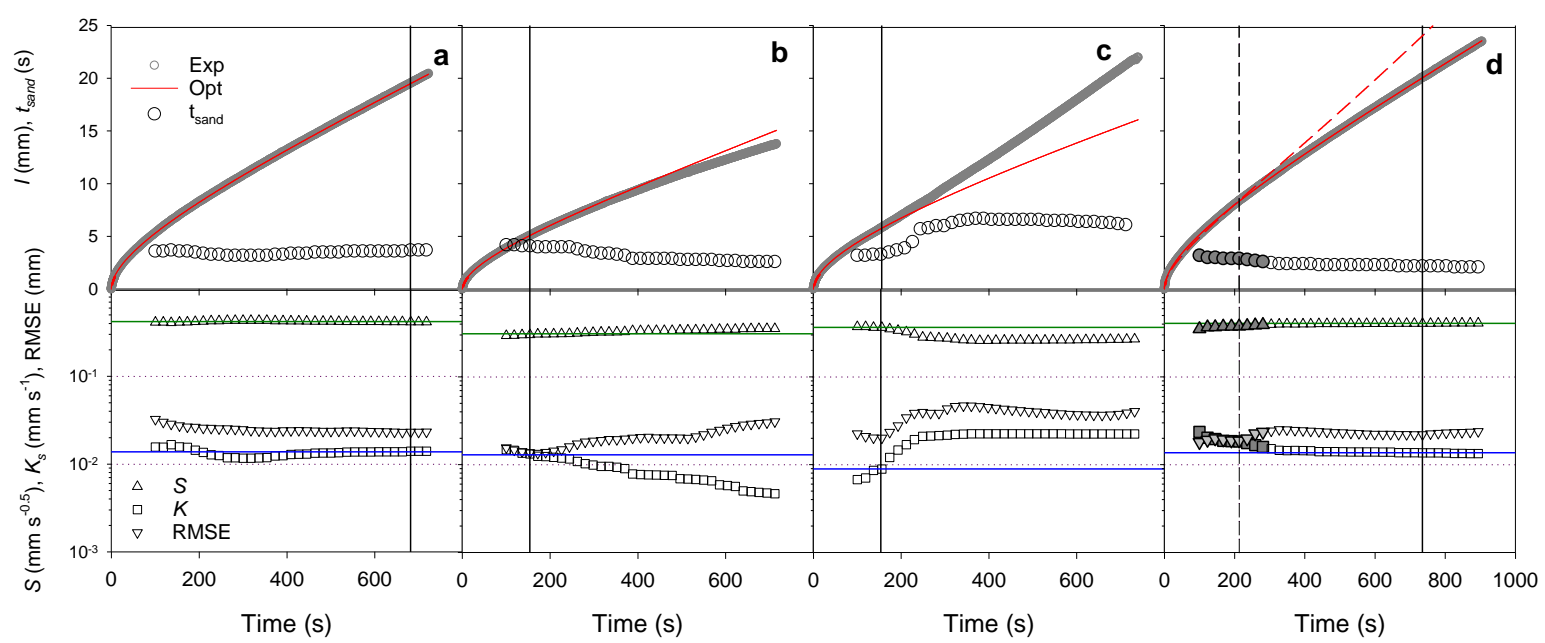

647

Figure 7. 